\section{Fluoride, immunity and tooth decay}

SIR-Diesendorf ${ }^{1}$ has raised fundamental questions about the supposed benefits of fluoridation in preventing tooth decay. May the debate continue.

As to why tooth decay in developed countries has declined, consider the following: the usual and first explanation for a marked fall in the incidence of any infectious disease is the acquisition of specific immunity to the causative organism by a significant proportion of the population at risk. Specific immunity may be acquired naturally or artificially (vaccination). Naturally acquired specific immunity may explain the decline in caries in developed countries. Tooth-brushing is now widespread in pre-school children and as many as 75 per cent of children may be brushing their teeth by the age of 18 months ${ }^{2}$. Current techniques teach children to brush the gums gently as well as the teeth. The bristles of a tooth-brush together with the mild abrasives found in toothpaste make an ideal instrument for transferring and implanting antigenic material from around the teeth, that is, decaycausing bacteria, into the oral mucus membranes.

The mouth possesses an immune system, and murine oral mucosa, at least, contains both the effector and regulatory cells required for the local production of immunoglobulin ${ }^{3}$. Brushing the gums with a contaminated brush may therefore produce a massive antigenic challenge resulting in the production of SIgA immunoglobulins ${ }^{4}$. The immunoglobulins may then cross cell barriers into the oral fluids, or they may form an SIgA-mucin complex on the surfaces of teeth. In either location they may interfere with the ability of decay-causing bacteria to attach to teeth.

56 Surrey Road,

Melbourne 3141,

Victoria, Australia

1. Diesendorf, N. Nature 322, 125-129 (1986)

2. Dowell, T.B. Br. dent. J. 150, 247-249 (1981).

3. Deslauriers, N., Neron, S. \& Mourad, W. Immunology 55, 391-397 (1985).

4. Smith, G.E. Trends pharmac. Sci. 7, 108-112 (1986)

SIR-Mark Diesendorf's account of "the mystery of declining tooth decay" ignores the study of the effects of fluoridation in Anglesey ${ }^{1}$, which was conducted under strictly blind conditions. This study clearly demonstrated a reduced incidence of dental caries in children in fluoridated Anglesey, as compared with controls living in non-fluoridated Bangor and Caernarfon. A secular reduction in the incidence of caries was observed in both communities between 1974 and 1983, possibly related to the increased use of fluoridated toothpastes, but in fluoridated Anglesey there was an additional reduction, particularly in the incidence of approximal attacks of molar and premolar teeth.

\section{Division of Biochemistry,}

Francis B. ReED

United Medical and Dental Schools of

Guy's and St Thomas's Hospitals,

Guy's Hospital, London SE1 9RT, UK

1. Jackson, D., James, P.M.C. \& Thomas, F.D. Br. dent. J. 158, 45-49 (1985).

\section{Classical caries}

SIR-Wyborny and Shannon' ${ }^{1}$ expose the lack of "classicism" in Coca-Cola. They also discuss the possible cariogenicity of various forms of this beverage. The "FASEB report" 2 noted that several investigators "found sucrose to be the most cariogenic substance among sugars and foods tested in animal experiments", but in other studies, glucose, fructose and other sugars were "almost as cariogenic as sucrose". Cariogenicity was related to adherence to the teeth by foods. A 10 per cent sucrose rinse was no more productive of low plaque $\mathrm{pH}$ values than were several other foods, including wheat flakes ${ }^{3}$.

Wyborny and Shannon speculate that either increases or decreases in dental caries may result from changes in CocaCola. This might be difficult to assess in view of the current decrease in dental caries attributed to water fluoridation and fluoride dentifrices ${ }^{4}$.

Classically speaking, Aristotle observed that "soft, sweet figs adhered to the teeth and produced damage".

\section{Department of Biophyics}

Thomas H. JukES

and Medical Physics,

University of California,

Berkeley, California 94720, USA

1. Wyborny L.E. \& Shannon, I.L. Nature 322, 21 (1986).

2. Evaluation of the Health Aspects of Sucrose as a Food Ingre dient (SCOGS-69), (Federation of American Societies for Experimental Biology, Bethesda, Maryland, 1976).

3. Jensen, M.E. \& Schactele, C.F. J. dent. Res. 2, 889-892 (1983).

4. J. Am. dent. Ass. 105, 75-79 (1982)

\section{Prelude to space}

SIR-May I correct your News item about space vehicles (Nature 322, 98; 1986)?

I certainly never claimed to have "invented" the idea of air-breathing engines for space vehicles 40 years ago. The concept is much older.

I merely said that I had described a (nuclear-powered!) horizontal take-off air breather in the novel Prelude to Space in about 1948 .

"Leslie's House",

Arthur C. Clarke

25 Barnes Place,

Colombo 7, Sri Lanka

\section{Anadin not anodyne}

SIR-In the editorial "Second chance for nuclear power?" (Nature 323, 1; 1986) you likened the switching off of safety systems at Chernobyl to a person with angina attempting to hide the pain by swallowing aspirin. Far from it: swallowing aspirin is a good bet, at least for those patients with unstable angina ${ }^{1.2}$.

J.M. RITTER G.W. TAYLOR

Royal Postgraduate Medical School, Hammersmith Hospital,

Ducane Road,

London W12 OHS, UK

1. Lewis, H.J. Jr et al. New Engl. J. Med. 309, 396-403 (1983) 2. Cairns. J A et al. New Engl. J. Med 313, 1369-1374 (1983).

\section{Poe's universes}

SIR-I read with interest and approval E. Harrison's article on Kelvin and the Olbers paradox (Nature 322, 417; 1986). I was glad to see that Edgar Allan Poe and his masterpiece Eureka were once more rehabilitated in a scientific magazine. Eureka contains a diversity of ideas and visions that show that Poe was far ahead of his time.

I do not, however, agree with Harrison when he says that Poe means 'galaxy' when he writes 'universe', because this does not do justice to Poe, who was a careful writer. The words 'universe' and 'galaxy' are often used in Eureka, and they are not freely interchangeable.

The point is that Poe did have a vision that closely resembled a concept nowadays called "multiple", "parallel" or "simultaneous" universes in different dimensions (and therefore unknowable to each other). Harrison quotes only the first sentence, but only with the above explanation does the whole paragraph make sense:

Let me declare only that, as an individual, I myself feel impelled to fancy - without daring to call it more - that there does exist a limitless succession of Universes. more or less similar to that of which we have cognisance - to that of which alone we shall ever have cognisance - - at the very least until the return of our own particular Universe into Unity. If such clusters of clusters exist, however - and they do - it is abundantly clear that, having had no part in our origin, they have no portion in our laws. They neither attract us, nor we them. Their material - their spirit is not ours - is not that which obtains in any part of our Universe. They could not impress our senses or our souls. Among them and us - considering all for the moment, collectively - there are no influences in common. Each exists, apart and independently, in the bosom of its proper and particular God!.

Boomstede 696,

E.R. van Slooten

3608 BT Maarssen

The Netherlands 